\title{
Narration of Featured Landscapes for Urban Culture
}

\author{
Qingxi Fan \\ School of Packaging Design and Art \\ Hunan University of Technologe \\ Zhuzhou, Hunan, China
}

\begin{abstract}
Taking three aspects of memorial, landmark and thematic featured landscapes as starting points, the paper aims to discuss the significance of such featured landscapes for recalling the urban history, telling city stories and revealing the theme of city. With the case method adopted, the paper deeply analyzes the emotional power brought by anti-fascist memorial landscapes in Berlin, the creative advertisement of the "King Bladud's Pigs in Bath" Art Project for cities and the "theme foil" of Zhuzhou fairy-dragon culture sculptures. We hereby conclude that: the urban culture invisible, while the landscape design is a visible carrier, which can make people living or walking in cities intuitively feel the power of culture and realize the responsibility of inheriting city culture.
\end{abstract}

Keywords -featured landscapes; sculpture; landscape design

\section{INTRODUCTION}

Settings can be read. Reading a setting means to understand it: what is going on; what happened; what will happen; how it connects with other places; etc. The historical trace in every place will be protected and recognized and corrected by people as past viewpoints. Artifacts such as the wood, soil and minerals that can explain cultural traditions are considered as landscape resources, which are preserved in the real and changing settings as far as possible. "The culture is the accumulation of the history, persists in cities and architectures and integrates in people's lives, which has invisible effects for the construction of cities as well as concepts and behaviors of citizens and is the soul for cities and architectures." The civilization is of inconsistency not only for the coherence of symbolic forms, but also for the self-preservation of these symbolic forms. The landscape is exactly the form, by which cultural groups are created and human's own personality is preserved. The Venice Charter promulgated by the United Nations Educational, Scientific and Cultural Organization (UNESCO) in 1964 has clearly indicated that: "the concept of a historic monument embraces not only the single architectural work but also the urban or rural setting in which is found the evidence of a particular civilization, a significant development or a historic event."1

\footnotetext{
${ }^{1}$ The Venice Charter is the international principles to protect monuments and sites with the full name of International Charter for the Conservation and Restoration of Monuments and Sites. On May 25-31, 1964, the International Council on Monuments and Sites held a meeting in Venice and passed the Venice Charter, which affirmed the importance values and roles of monuments and sites and considered them as the common heritage of humans and the witness of history.
}

In cities, the historical context and culture mark will form a tone without noticing and make people living or walking in these cities feel the tone. Certain things silently remind cities and people in these cities that: some memories will never be forgotten; certain stories must be listened to more; some beauty must be created together. And featured landscapes are such an existence.

\section{BERLIN “ANTI-FASCIST” MEMORIAL LANDSCAPE DESIGN-IN MEMORIAM OF HISTORICAL EVENTS}

The architectural development history of a city generally corresponds to a long history city, which is of certain memorable significance. Such memorial feature is more concrete on specific memorials or memorial architecture. Either for the pride of victory and triumph, the memoriam of war wounds or the eulogization of revolutionary martyrs, the successful memorial design brings people with the infinite spirit and infectious power.

Berlin is a city full of historical memorial significance. The World War II, Jews...these histories seem to become indelible imprints, which are faithfully stated by artists in various forms of monuments, memorials and memorial buildings. After 60 years since the Nazi regime has been defeated, it is still hard for modern artists in Germany to separate monuments here with the fascism in the past. For them, the educational logic of monuments is to make people continue to recall features that are too closely associated with the Nazism.

Randomly walk in streets of Berlin, several metal pieces next to each other underfooting attract our visual attention. Carefully read letters and figures on these pieces, and these are names and times. Such articles are exactly the metal copper pieces laid by the artist Gunter Demnig. Compared to common pavements, the brass stone blocks are higher for a few pages and called "stumbling blocks". "Fig. 1" Demnig believed that: many victims during the Nazi occupation were not completely voluntary to leave their own places of residence in those years; we should let them "return back". Therefore, copper stone blocks are set on the ground in front of gates for "final choices of residence" of victims. For some people, the dignity of dead Jews has been trampled once again. For descendants of victims, however, these stone blocks are souvenirs that touch the soul the most. The descendant of a Jewish survivor once wrote after seeing these little stone blocks: "victims should never be forgotten. 
And the massacre is exactly a stumbling block for the world history!"

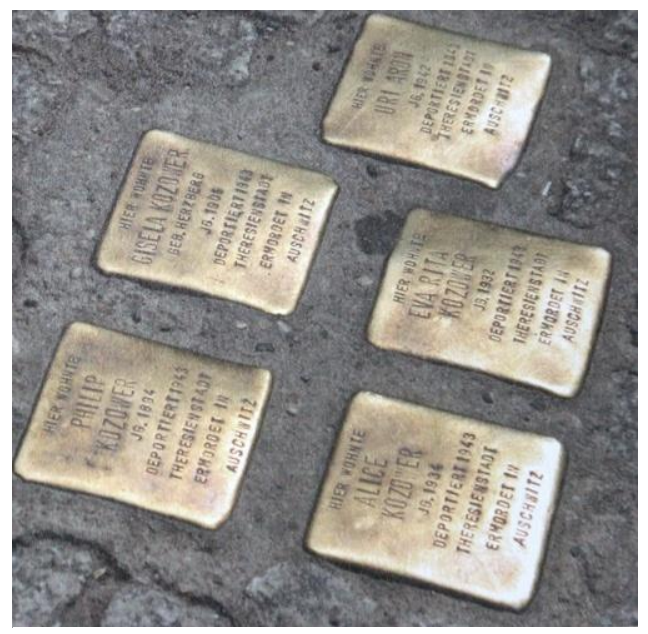

Fig. 1. "Stumbling Blocks"

It is true that the commemoration culture is not the subject of denunciation at all. When violently attacking the German historicism oppressing lives in the stupid past form in the 19th century, Nietzsche has claimed that: "we should keep away from monument squares". For that, many artists and cultural historians began the consistent denouncement as well. In the 1930s, Lewis Mumford wrote that: "stones bestow on us the uniformly continuous, the misleading life confidence." He even said that: "they inscribe the selfdramatizing glory onto the monument; write the performance onto the obelisk; place the hope to be memorialized onto one and one solid stones so as to dedicate forever their subjects or descendants. However, they have forgotten the fact that compared to lives not protected or preserved by stones, these stones abandoned by lives are even more futile."

Or the emergence of "anti-monument" matters leads a new way for German designers distressing in conflicts. The memorial space here is considered as the challenge for conventional premise of monuments. In fact, the conventional memorials will conserve the memory and then completely disappear from the consciousness. People facing these memorials every day, will not deepen the memory of these events, but slowly transfer such memorials into visual habits. Therefore, the concept of "anti-monument" is not the one of counter-memory, but the fact that we must depend on an opposite wish to forget them when finding that memorials will only replace the memory. The "Pease, Anti-war \& Antifascist Monument" designed and constructed by Jochen Gerz and Easther Shalve-Gerz in Hamburg-harburg is built on the mentality exactly. The Monument is a memorial column of $12 \mathrm{~m}$ high and one meter square composed of hollow aluminum with a thin layer of soft dark-color lead. On each corner, a rope with a stylus is fixed to depict on the soft lead layer. It is odd that, however, when the section of $1.5 \mathrm{~m}$ high on the Monument is full of memorial scrawls, the Monument will sink down and into a basement as deep as the column height. In other words, the more positive visitors are, the faster the Monument will disappear. Since the Monument is completed in 1986, all that is left is just the flat of the Monument after several sedimentations in the next seven years, and it is covered by a tombstone inscribed with the "Hamburg Anti-fascist Monument". In this process, the Monument returns the burden of memory to visitors inch by inch, which plays an "anti-index" function for the time and memory of memorial sites as well as the pattern of the present history having the interaction role.

\section{SyMBOLIC DESIGN OF BATH "PIGS"-NARRATION OF CITY STORIES}

To "narrate" is actually to tell stories, which is an instinctive means of expression of people. The narration derives from the Latins "gnarus" and "to know", which implies a means to obtain the knowledge through the occasionality of behaviors and experience. For the expression of landscapes, we generally understand it as the explanation of symbols and endow it with contents and significance of contexts. Meanwhile, the landscape planning is just like the wording, and there are implied meanings between the lines as well. In "narrating" landscapes, the city stories are written with corresponding grammars, related allusions and idioms cited and imported terms added. The same as the literature, there are also many styles, techniques and ways of interpretation for landscapes. And the ripples occasionally stirred up in heart by landscapes become the power source to live in cities.

The same as the "bear" in Berlin and "cow" in Chicago, Bath famous for hotspring in London suburbs also has the proud pig complex. Pig sculptures made of various materials and colors are all members of the art project of "King Bladud's Pigs in Bath". "Fig. 2" Such sculptures are set on every corner of cities and each pig has sponsor, artist and its own name. These pig sculptures are to raise funds for a road of four miles in a narrow sense; but derive from a memorable story of appreciation. The story dates back to the Celtic era. Back then the Prince Bladud in UK has suffered from a serious skin disease and been exiled to a country for raising pigs. Unintentionally, he found that pigs often roll about in a pond with strange smell. When driving these pigs, he conveniently bathed in a hotspring besides the pond. As time passed, the hotspring water with mineral substances cured his lepriasis unexpectedly. After succeeding to the throne, he sent someone to test the hotspring water. It was found that being rich with mineral substances such as sulphur, which is effective to diseases of certain nervous system and skin. Therefore, he ordered to dig a deep well to pump the hotspring water underground and store it into the giant stone pond to largely build the "ROOMBATH" following the ancient Rome style. And the English meaning of bath is "bath pond".

Florid decorations of temples, great graphics of designers and pigs wearing cloths of various materials, take people to feel the cultural metropolis full of rich stories. More than that, in the public art activity conducted in the name of "King Bladud's Pigs in Bath", the following targets are proposed then: stimulate the development of regional industries through art work; provide opportunities for regional artists to 
achieve the works activities and thoughts; bring visitors and residents with joy; propagandize Bath; raise funds with good motivations for the regional development. The pig plan of Bath is not furnishings simply providing the visual enjoyment, but the art of historical and social contexts that can be easily contacted in the daily life. Thus, it not only determines the nativeness, but also plays the pivot role for bringing the commercial success and social innovation of regions.

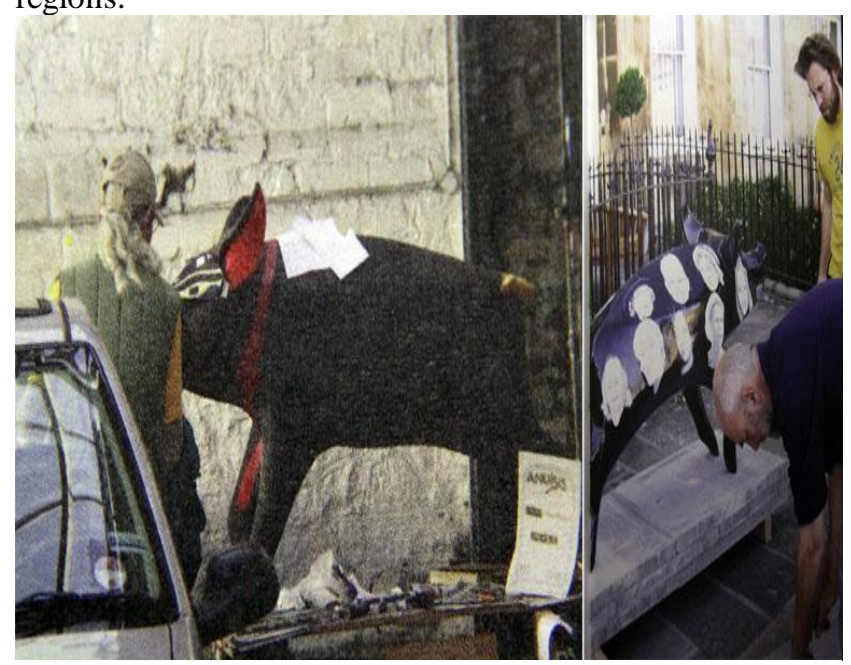

Fig. 2. Bath Pigs

\section{EMBELLISHMENT OF ZHUZHOU "FAIRY-DRAGON} LANDSCAPE SCULPTURES" - RECALLING THE THEME OF CITY

In each city, there are places that can make people feel and show the wisdom and art, which is just like the oasis in the desert that makes us be concerned and yearn for as well as be full of creativity. A famous saying of Eliel Saarinen stated that: "let me see your city, and I can say what citizens in the city are seeking for in the aspect of culture."

Zhuzhou is one of the birthplaces of the traditional Chinese culture. In the Luyuanpo, Yanling County of Zhuzhou, ancient records tell that Emperor Yan Shen Nong Shi, one ancestor of the Chinese nation and jointly named with Emperor Huangdi was buried here (the Emperor Yan Mausoleum initially built in the Song dynasty has been restored now). The ancient book recorded that, the Flame Emperor Shen Nong Shi "first making tilling tool and teach people to farm; taste all herbs to invent the medicine; spin thread as cloth to make clothes; exploit markets first to exchange of needed goods; cut tung tree to make musical instrument, form silk to make strings and make the quinton; make wood as arc, carve wood as arrows and deter the world." These six achievements of the Emperor Yan creates the Chinese agriculture culture, creates the earliest civilization of the ancient China and then ends the history of ancient human depending on venisons and wild fruits, which drives the ancestors to enter the agriculture civilization.
In Zhuzhou, marks of fairy-dragon culture are clearly visible. Relying on the deep Emperor Yan culture, Zhuzhou conducts the qualitative transformation based on the original Emperor Yan Square by taking such square as the center, regarding the fairy-dragon culture as the theme and considering the influence of Emperor Yan on the yin/yang and the history of pottery invention as background. "Fig. 3" The main building on the Fairy-dragon Square is a fairydragon figure of $19.97 \mathrm{~m}$ high, which implies that the square was built in 1997 A.D. Shen Nong Shi, wearing ox horn over the head, carrying a herb basket and holding a tilling tool, is represented with the cultural pioneer spirit of "first making tilling tool and tasting all herbs". Under the giant statue, it is centered with a base representing the "God of the Sun" as well as large-scale relief and totem poles by taking the eulogizing of great achievements of Emperor Yan as themes. Besides, soils from lands of China are also collected for the fairy-dragon figure, which gathered 34 pieces of peculiar soils nationwide for the base establishment and statue. What facing towards the fairy-dragon figure is an antique stone figure - sundial (an instrument used for computing time in the past), which represents the grasp of time of ancestors. Right behind the figure and in front of the fairy-dragon tower, there is a solar-energy stream, which either flow slowly or fast as the waterfall. The sculptures along the stream, such as the "Transactions of Commodities", "Forming Silks as Strings" and "Making Wood as Arrows", represent the agricultural-culture scenes created by the Emperor Yan seven thousand years ago, which injects the new meaning to the modern square.

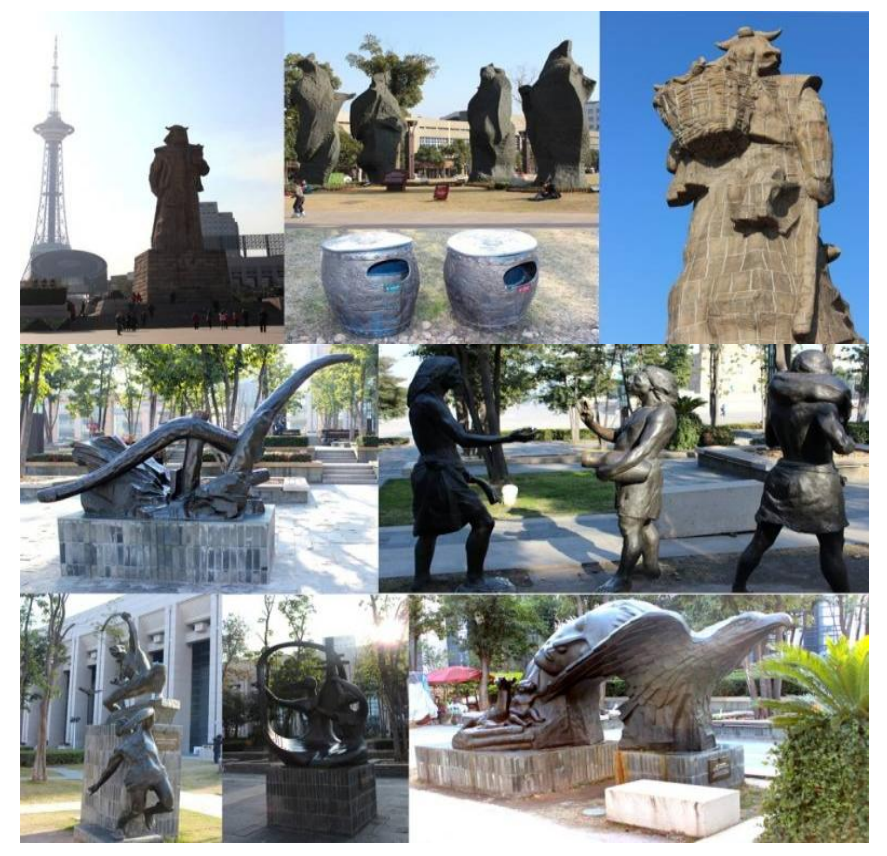

Fig. 3. Emperor Yan Square in Zhuzhou

The large-scale water-screen film beside the fairy-dragon tower corresponds to the scenes and occasions, tirelessly telling the story of Shen Nong Shi. And the ripples of ancient culture undulate silently in everyone's heart. The "Yandi tribe" along the Fairy-dragon Lake is composed of ancient 
buildings such as memorial archway, meeting hall, tribe dwellings and watchtower, which are the most intuitive representation for the fairy-dragon culture. The fairy-dragon altar is the place for blessing and sacrificing of the Shennong city. Climb steps with the respect and enter the sacrifice temple with solemnity. And the stone sculptures and buildings integrating with cultural symbols of the Emperor Yan all sublimate the atmosphere.

As a medium-sized city, Zhuzhou can rely on the carrier of "Emperor Yan Mausoleum Fiesta" that integrates the national sentiments of Chinese globally, and creates the new city open space-Shennong City integrated with the landmark buildings and landscapes. Therefore, Zhuzhou do have certain considerations for inheriting the urban context and is certainly the model of thematic city construction nationwide.

\section{REFERENCES}

[1] Steven C. Bourassa. The Aesthetics of Landscape. London: Belhaven Press, 1991: 91

[2] Lewis Mumford, The Culture of Cities, New York: Harcourt, Brace, Javanovich, 1938:438.

[3] Li Kairan. Concepts of "Meaning, Background \& Enlightenments" for Landscapes and Semantics Interpretation [J]. Chinese Landscape Architecture. 2008 (3). 91

[4] Jin Xuanwo. Translated by DrMaster Press. Economic Power of Aesthetics-Design Management and Brand Management of European Designers [M]. Beijing: Publishing House of Electronics Industry, 2011: 165. 